\title{
Modelowanie naprężeń własnych w procesie przetapiania mikroplazmowego powłoki Al na stali
}

\author{
Modeling of residual stresses in the process of microplasma \\ remelting of Al coating on steel substrate
}

\section{Streszczenie}

W pracy zaprezentowano wyniki modelowania naprężeń własnych w warstwie FeAl powstałej w procesie przetapiania mikroplazmowego powłoki aluminiowej natryskanej uprzednio na podłożu stalowym. Zbudowano płaski model numeryczny (MES) układu warstwa FeAl-podłoże stalowe o wymiarach odpowiadających rzeczywistym próbkom. Przeprowadzono analizę sprzężoną cieplno-mechaniczną, w której parametry przetapiania odpowiadały tym, które zapewniały tworzenie się warstwy FeAl na podłożu stalowym. Analiza wykazała występowanie rozciągających naprężeń własnych w warstwie międzymetalicznej oraz ściskających w podłożu stalowym. Dodatkowo, przeprowadzono pomiary wygięcia rzeczywistych próbek z wytworzoną warstwą FeAl, które posłużyły do weryfikacji modelu numerycznego.

Słowa kluczowe: warstwy FeAl; przetapianie mikroplazmowe; naprężenia własne; modelowanie MES; krzywizna wygięcia

\section{Abstract}

The paper presents the results of residual stress modeling in FeAl surface layer produced in the process of microplasma remelting of aluminum coating previously sprayed onto a steel substrate. The plane stress numerical model (FEM) of FeAl-steel substrate system with geometry and dimensions reflecting real samples has been built. The coupled thermo-mechanical analysis has been conducted in which the remelting parameters ensuring formation of FeAl surface layer were used. The analysis showed the existence of tensile residual stresses in the intermetallic layer and compressive stresses inside the substrate material. Additionally, the conducted deflection measurement of produced samples with FeAl layer allowed to verify developed numerical model of analyzed FeAl/steel system.

Keywords: FeAl layers; plasma remelting; residual stresses; FEM modeling; curvature measurements

\section{Wstęp}

Prace nad rozwojem i zastosowaniem materiałów intermetalicznych prowadzone są w wielu ośrodkach naukowych. Obecnie najczęściej stosowanymi materiałami na bazie faz międzymetalicznych są materiały z układów Fe-Al, Ti-Al oraz Ni-Al. Najciekawszym materiałem ostatnich lat, ze względu na koszt materiałów podstawowych, są stopy z układu Fe-Al, z kolei ze względu na właściwości mechaniczne - stopy z układu Ti-Al.

Materiały na bazie uporządkowanych faz międzymetalicznych z układów Fe-Al oraz Ti-Al charakteryzują się wysoką wytrzymałością i odpornością na utlenianie, a także małą gęstością. Mogą pracować w temperaturze powyżej $900{ }^{\circ} \mathrm{C}$ utrzymując przy tym stabilność struktury i wiązań chemicznych. Między innymi dlatego znajdują obecnie szerokie zastosowanie w przemyśle energetycznym, motoryzacyjnym, lotniczym, a także spożywczym [1,2].

W niniejszym rozdziale zamieszczono wyniki badań nad nowymi metodami wytwarzania warstw intermetalicznych na podłożu stalowym. Wykorzystano procesy technologiczne wywodzące się z tradycyjnych metod z zakresu inżynierii spajania z wykorzystaniem skoncentrowanego źródeł ciepła. Polegało to na wytwarzaniu warstw powierzchniowych w procesie dwuetapowym składającym się z łukowego natryskiwaniu czystego glinu na podłoże stalowe, a następnie przetopieniu uzyskanej powłoki wraz z częścią materiału z podłoża za pomocą skoncentrowanego strumienia plazmowego. W efekcie $\mathrm{w}$ procesie przetapiania powstały warunki umożliwiające utworzenie in-situ warstwy powierzchniowej zawierającej FeAl co potwierdzone zostało pomiarami twardości oraz rentgenowską analizą fazową analizowanych warstw [3]. Obecnie, wytwarzane warstwy intermetaliczne poprzez natrysk cieplny gotowymi (komercyjnymi) proszkami na bazie faz międzymetalicznych są bardzo kosztowne. Dodatkowo takie warstwy mają skłonność do rozwarstwiania się, charakteryzują się wysoką porowatością oraz ograniczoną przyczepnością do podłoża.

Dr inż. Jolanta Zimmerman; dr hab. inż. Dariusz Golański, prof. PW; dr hab. inż. Tomasz Chmielewski, prof. PW - Politechnika Warszawska.

Autor korespondencyjny/Corresponding author: 
Natomiast proces przetapiania pozwala na uzyskanie drobnoziarnistej struktury materiału podstawowego. Dzięki takiej obróbce często zostają zlikwidowane defekty struktury po obróbce plastycznej, a materiał podstawowy uzyskuje wysoką jednorodność i odporność na zmęczenie [4]. Połączenie tych dwóch procesów (natryskiwania oraz przetapiania) pozwala na uzyskanie warstw na bazie faz międzymetalicznych oraz właściwości charakteryzujące warstwy przetapiane [5].

Jednym z ważniejszych problemów towarzyszących procesom wytwarzania warstw powierzchniowych jest zagadnienie naprężeń własnych. Powstają one podczas chłodzenia układu warstwa-podłoże powstałego w podwyższonej temperaturze i wynikają głównie z różnicy właściwości cieplno-fizycznych między materiałami warstwy i podłoża [6]. Niekorzystny stan naprężeń własnych w warstwie czy też na granicy warstwy i podłoża może doprowadzić do powstawania pęknięć w warstwie, jej odwarstwiania się od podłoża, a w końcowym efekcie zniszczenia warstwy obniżając trwałość eksploatacyjną danego wyrobu [7]. W celu oszacowania stanu naprężeń własnych jaki powstaje w układzie warstwy międzymetalicznej typu Fe-Al, powstałej poprzez przetapianie mikroplazmowe stalowego podłoża z natryskaną powłoką z glinu przeprowadzono symulację numeryczną metodą elementów skończonych naprężeń własnych w modelu odzwierciedlającym próbki, dla na których wytwarzano warstwy FeAl. Dodatkowo, przeprowadzono pomiary wygięcia rzeczywistych próbek z przetopioną warstwą (FeAl) w celu weryfikacji opracowanego modelu numerycznego.

\section{Modelowanie naprężeń własnych}

Przeprowadzono modelowanie numeryczne naprężeń własnych generowanych w czasie przetapiania powłoki Al na podłożu S235JR (98,5\% Fe). Warunki modelowania odpowiadały rzeczywistym próbom przetapiania, w wyniki których wytworzona została warstwa międzymetaliczna FeAl o średniej grubości powłoki FeAl po przetopieniu 0,25 mm, (grubość podłoża stalowego wynosiła $2 \mathrm{~mm}$ ). Wytworzona warstwa obejmowała prostokątny obszar o wymiarach $30 \times 20 \mathrm{~mm}$. Warstwa FeAl została wytworzona wielościegowo przy szerokości pojedynczego ściegu wynoszącego $3 \mathrm{~mm}$.
Przeprowadzając analizę wytrzymałościową takiego układu przy użyciu metody elementów skończonych, napotykamy problem związany ze skalą wymiarów grubości powłoki w stosunku do grubości podłoża. Zbudowanie modelu przestrzennego (3D) MES rzeczywistej geometrii takiej konstrukcji spowodowałoby znaczne jego rozbudowanie z powodu zagęszczenia elementów na powłoce i w okolicach powierzchni granicznej. Konsekwencją tego jest znaczny spadek efektywności obliczeń, co prowadzi do znaczącego wydłużenia w czasie obliczeń oraz kosztów modelowania. $Z$ tego powodu analizowane zagadnienie zostało uproszczone do płaskiego stanu odkształcenia. W procesie przetapiania stosowano zachodzące na siebie ściegi o szerokości $3 \mathrm{~mm}$ co przy całkowitej szerokości próbki wynoszącej $20 \mathrm{~mm}$ stanowiło wymiar kilkukrotnie mniejszy. Umożliwiło to przyjęcie założenia, że w warstwie nie będą występowały odkształcenia w trzecim kierunku.

\section{Model numeryczny układu warstwa FeAl/podłoże Fe}

Modelowanie naprężeń powstających w czasie przetapiania i chłodzenia powstałej warstwy FeAl na podłożu stalowym przeprowadzono $z$ wykorzystaniem metody elementów skończonych przy zastosowaniu programu ADINA 8.6 z modułami "Thermal” i "Structure" umożliwiającymi sprzężoną analizę termo-mechaniczną. Z uwagi na ograniczenia programu co do możliwości ciągłego przemieszczania się źródła ciepła, w zbudowanym modelu zastosowano takie rozwiązanie, w którym wydzielono kilka obszarów na warstwie przetapianej o szerokości 3 mm (równej szerokości pojedynczego ściegu), do których w sposób dyskretny przykładane było obciążenie działające przez $1 \mathrm{~s}$, kolejno w każdym z tych obszarów. Obciążenie to było zadane poprzez strumień ciepła równy $q=10,8 \mathrm{~W} / \mathrm{mm}^{2}$, wyliczony na podstawie obliczonej energii wprowadzonej przez zastosowane źródło ciepła w postaci strumienia mikroplazmowego o następujących parametrach: natężenie prądu I = $25 \mathrm{~A}$, napięcie łuku $U=11,7 \mathrm{~V}$, sprawność procesu $\eta=0,7$ ). Czas działania obciążenia cieplnego na początku każdego ściegu wyliczony został z prędkości przesuwu palnika wynoszącej v = $15 \mathrm{~mm} / \mathrm{min}$.

Tablica I. Własności termomechaniczne stopu FeAl przyjęte do analizy Table I. Thermomechanical properties of FeAl alloy assumed for analysis

\begin{tabular}{|c|c|c|c|c|c|c|c|c|c|}
\hline $\mathrm{T}\left[{ }^{\circ} \mathrm{C}\right]$ & 20 & 200 & 400 & 500 & 600 & 700 & 800 & 900 & 1000 \\
\hline $\mathrm{C}_{\mathrm{p}}[\mathrm{J} / \mathrm{kgK}]$ & 0,56 & 0,62 & 0,66 & 0,68 & 0,70 & 0,72 & 0,75 & 0,80 & 0,85 \\
\hline $\boldsymbol{\lambda}[\mathrm{W} / \mathrm{mK}]$ & 9,8 & 12,3 & 14,5 & 15,3 & 16,0 & 16,5 & 16,9 & 17,1 & 17,1 \\
\hline $\mathrm{E}[\mathrm{Ga}]$ & 260 & 260 & 260 & 260 & 260 & 260 & 260 & 260 & 260 \\
\hline $\mathrm{R}_{\mathrm{e}}[\mathrm{MPa}]$ & 380 & 350 & 320 & 280 & 280 & 280 & 100 & 40 & 40 \\
\hline $\boldsymbol{a} \cdot 10^{-6}[\mathbf{1} / \mathrm{K}]$ & 16,0 & 18,0 & 19,8 & 20,2 & 20,8 & 21,4 & 22,0 & 22,8 & 23,6 \\
\hline
\end{tabular}

Tablica II. Własności termomechaniczne stali S235 przyjęte do analizy Table II. Thermomechanical properties of S235 steel assumed for analysis

\begin{tabular}{|c|c|c|c|c|c|c|c|c|c|c|c|}
\hline $\mathbf{T}\left[{ }^{\circ} \mathbf{C}\right]$ & 20 & 100 & 200 & 300 & 400 & 500 & 600 & 700 & 800 & 900 & 1000 \\
\hline $\mathbf{C}_{\mathrm{p}}[\mathrm{J} / \mathrm{kgK}]$ & 0,42 & 0,46 & 0,52 & 0,57 & 0,59 & 0,68 & 0,87 & 0,92 & 0,68 & 0,65 & 0,64 \\
\hline$\lambda[\mathrm{W} / \mathrm{mK}]$ & 65 & 60 & 55 & 51 & 46 & 42 & 36 & 33 & 31 & 28 & 25 \\
\hline $\mathbf{E}[\mathrm{Ga}]$ & 202 & 195 & 187 & 180 & 173 & 166 & 158 & 151 & 144 & 137 & 133 \\
\hline $\mathbf{R}_{\mathrm{e}}[\mathrm{MPa}]$ & 216,5 & 211,3 & 200,9 & 185,2 & 164,2 & 138,1 & 106,6 & 69,9 & 28,0 & 7,0 & 3,0 \\
\hline $\mathbf{a} \cdot 10^{-6}[\mathbf{1} / \mathrm{K}]$ & 12 & 12,5 & 13 & 13,5 & 13,9 & 14,4 & 14,8 & 15,3 & 15,7 & 16,1 & 16,4 \\
\hline
\end{tabular}


Na rysunku 1 przedstawiono geometrię zbudowanego modelu z zaznaczonymi wydzielonymi powierzchniami, do których przykładano strumień cieplny. Oznaczono także warunki brzegowe przemieszczeniowe przyjęte $\mathrm{w}$ modelu mechanicznym. Na krawędziach „K1" i „K2" (warunek „B”) zablokowano przemieszczenie w kierunku poziomym „z".

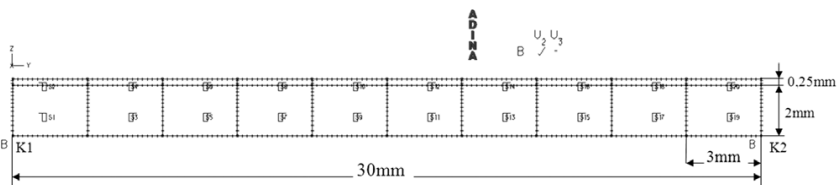

Rys. 1. Geometria z oznaczonymi warunkami brzegowymi modelu mechanicznego

Fig. 1. Geometry with boundary conditions of the mechanical model

W modelu termicznym zastosowano dwie grupy elementowe przewodzące odpowiednio dla podłoża Fe oraz powłoki FeAl, a także elementy konwekcyjne na brzegach. Przyjęto konwekcję swobodną ze współczynnikiem konwekcji równym $\mathrm{h}_{\mathrm{a}}=10 \mathrm{Wm}^{-2} \mathrm{~K}^{-1}$. Siatkę elementów skończonych modelu z oznaczeniem termicznych warunków brzegowych dla wybranych, przykładowych czasów obciążenia (1 s i 10 s) przedstawiono na rysunku 2.

Do obliczeń przyjęto właściwości cieplno-fizyczne $\left(\mathrm{C}_{\mathrm{p}}-\right.$ ciepło właściwe, $\lambda$ - przewodność cieplna, E - moduł Younga, $\mathrm{R}_{\mathrm{e}}$ - granica plastyczności, a - współczynnik rozszerzalności cieplnej) stopu FeAl w funkcji temperatury przyjęte na podstawie literatury $[8 \div 10]$.

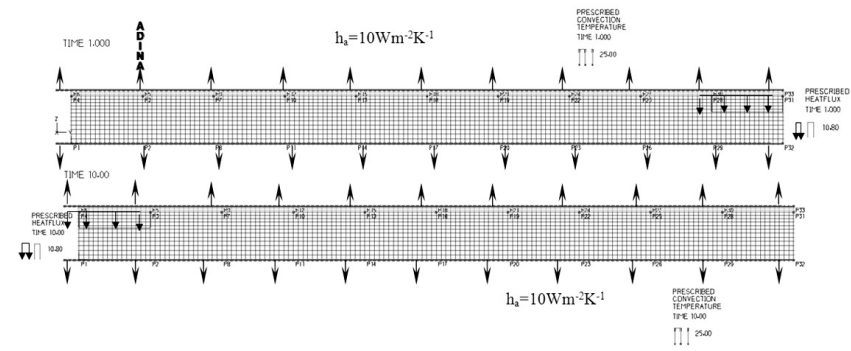

Rys. 2. Siatka MES modelu warstwa FeAl / podłoże Fe z oznaczeniem termicznych warunków brzegowych dla obciążenia w czasie 1 s i 10 s wykonywanych ściegów

Fig. 2. FEM mesh of FeAl layer / Fe substrate with thermal boundary conditions for load in $1 \mathrm{~s}$ and $10 \mathrm{~s}$ of runs made

\section{Wyniki obliczeń}

Na rysunku 3 zobrazowano rozkład temperatury w modelu w postaci map pola temperatury dla wybranych czterech czasów nagrzewania ściegów z początku, środka i końca fazy przetapiania. Widać, że wraz z pojawiającymi się

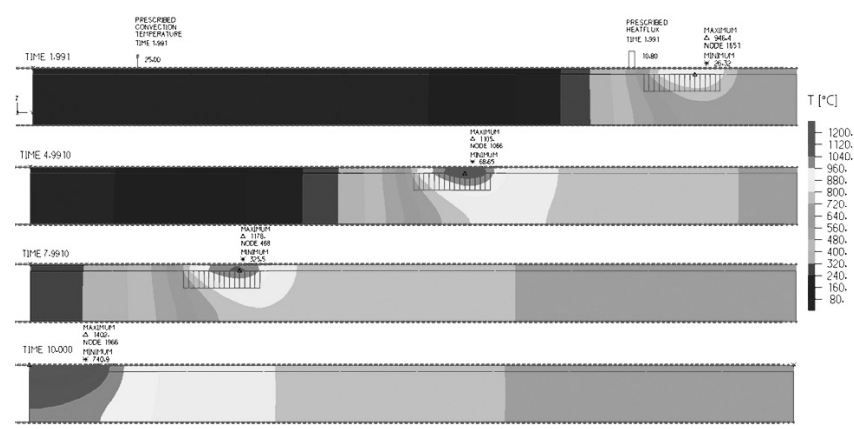

Rys. 3. Rozkład temperatury dla kolejnych wybranych czasów nagrzewania wydzielonych obszarów

Fig. 3. Temperature distribution for subsequent selected heating times of the separated areas kolejnymi ściegami wzrasta temperatura w całym układzie, widoczne są także gradienty temperatury o najwyższych wartościach w obszarze oddziaływania źródła ciepła.

Po zakończonym procesie nagrzewania (przetapiania) na skutek niestacjonarnego pola temperatury, powstających odkształceń plastycznych oraz zróżnicowania właściwości cieplno-fizycznych warstwy FeAl oraz podłoża stalowego po ostudzeniu do temperatury otoczenia w układzie pozostają naprężenia własne. Najistotniejsze naprężenie, w postaci mapy naprężeń składowej wzdłużnej $\sigma_{y y}$ przedstawione zostało na rysunku 4. Widać, że w utworzonej warstwie panują naprężenia rozciągające $w$ miarę równomierne rozłożone na całej szerokości warstwy o maksymalnej wartości dochodzącej do $128 \mathrm{MPa}$ po stronie FeAl przy samej granicy z podłożem. W podłożu metalowym naprężenia przechodzą od ściskających przy granicy z warstwą (ok. -50 MPa) do rozciągających od strony przeciwległej (ok. $40 \mathrm{MPa}$ ).

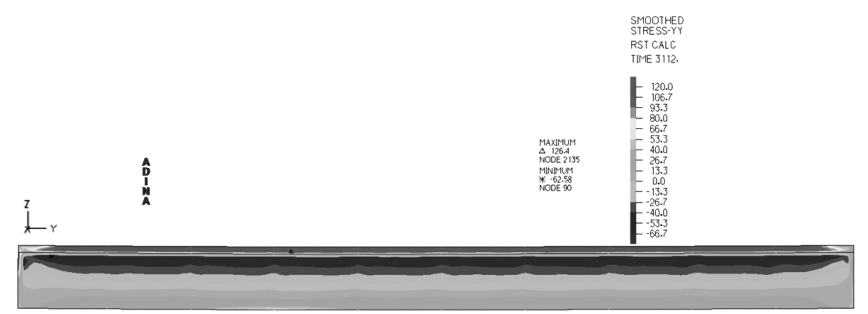

Rys. 4. Mapa naprężeń własnych $\sigma_{y y}$ w układzie warstwa FeAl / podłoże stalowe po ochłodzeniu do temperatury otoczenia

Fig. 4. Residual stress $\sigma_{y y}$ map of FeAl layer / steel substrate after cooling to ambient temperature

Rozkład składowej $\sigma_{y y}$ naprężeń własnych wzdłuż grubości układu warstwa/podłoże poprowadzony w płaszczyźnie symetrii próbki przedstawiono na rysunku 5.

$\mathrm{Na}$ skutek powstającego niestacjonarnego pola temperatury w czasie nagrzewania układ warstwa/podłoże ulega zmiennym deformacjom i po ostudzeniu całości do temperatury otoczenia doznaje wygięcia, którego maksimum jest przesunięte $w$ stosunku do płaszczyzny symetrii pionowej próbki. Widać to wyraźnie na zaprezentowanym rysunku 6 , gdzie na początkową geometrię modelu nałożono obraz zdeformowanej siatki MES w znacznie powiększonej skali (40x), dla momentu po wystudzeniu całego układu.

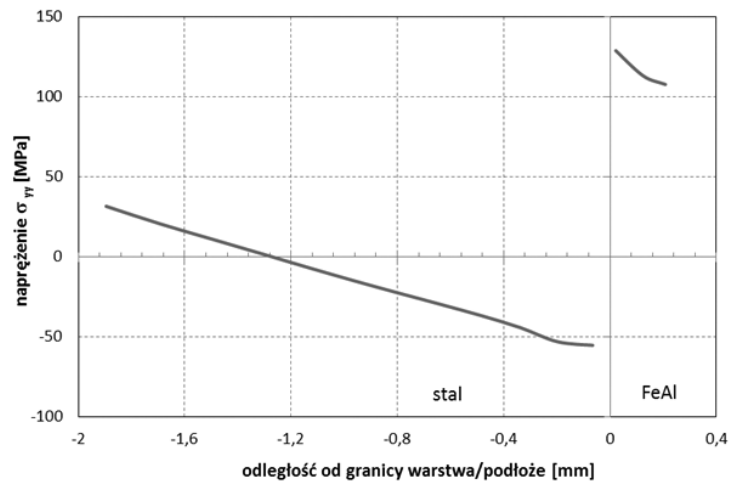

Rys. 5. Rozkład naprężeń własnych $\sigma_{y y}$ wzdłuż grubości układu warstwa FeAl / podłoże stalowe w jego płaszczyźnie symetrii

Fig. 5. Residual stress $\sigma_{y y}$ distribution along the thickness of the FeAl layer / steel substrate in its symmetry plane

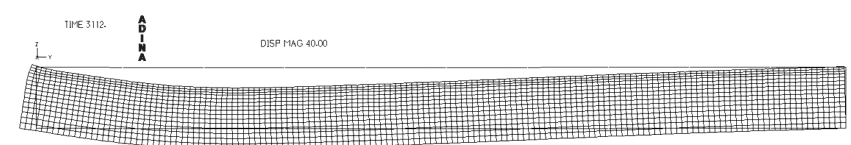

Rys. 6. Deformacja siatki modelu układu warstwa FeAl / podłoże Fe w powiększonej skali (40x)

Fig. 6. Deformation of the FeAl layer pattern grid system / Fe medium scale scale (40x) 
Na rysunku 7 przedstawiono wyznaczoną linię ugięcia układu poprowadzoną wzdłuż powierzchni warstwy. Maksymalne ugięcie układu pojawiło się w odległości $7 \mathrm{~mm}$ od pionowej osi symetrii próbki i wyniosło 0,01924 mm.

W celu weryfikacji modelu numerycznego przeprowadzono pomiary wygięcia próbek z wytworzonymi warstwami FeAl. Badania przeprowadzono przy użyciu specjalnie zbudowanego urządzenia pomiarowego opartego na cyfrowym czujniku zegarowym, wykorzystywanego również do pomiarów wygięcia próbek z natryskiwanymi powłokami [11].

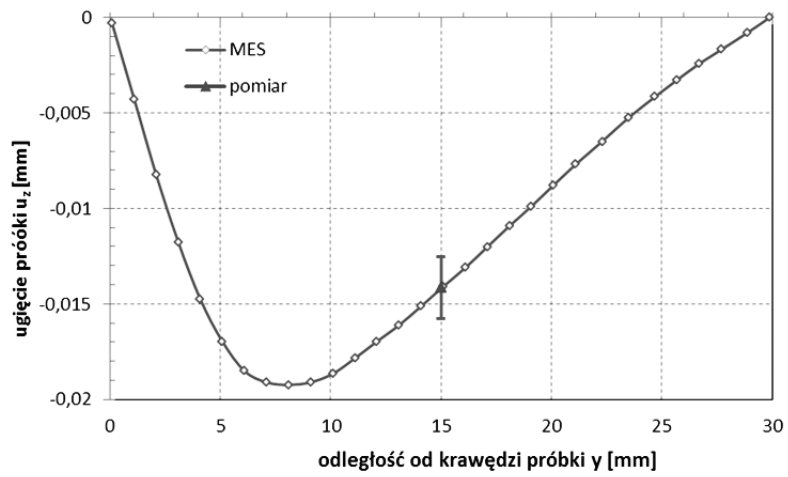

Rys. 7. Ugięcie modelu układu warstwa FeAl / podłoże Fe w kierunku "z" z naniesioną zmierzoną wartością ugięcia w rzeczywistej próbce Fig. 7. Deflection of the FeAl layer / Fe substrate in the " $z$ " direction with the measured deflection value in the actual sample
Badane próbki ze stali S235JR o wymiarach 20 x $30 \mathrm{~mm}$ i grubości $2 \mathrm{~mm}$ umieszczano w przyrządzie przed procesem wytwarzania warstw w celu wyzerowania wskazania czujnika pomiarowego. Po przetopieniu powłoki i wytworzeniu warstwy FeAl próbki ponownie umieszczano w przyrządzie, rejestrując ich wygięcie w połowie szerokości próbki. Zmierzone rzeczywiste średnie ugięcie próbek przetapianych łukiem plazmowym, mierzone $\mathrm{w}$ środku szerokości

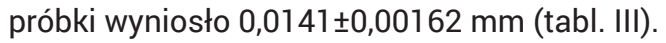

W analizowanym modelu numerycznym wygięcie próbki w płaszczyźnie symetrii układu (y = $15 \mathrm{~mm}$ ) osiągnęło wartość $\mathrm{u}_{\mathrm{z}}=0,0142 \mathrm{~mm}$. Świadczy to o dobrej zgodności wyników modelowania z rzeczywistymi pomiarami.

Tablica III. Zmierzone wartości ugięcia próbek przetapianych Table III. Measured deflections of melted specimens

\begin{tabular}{|c|c|c|c|}
\hline & Próbka 1 & Próbka 2 & Próbka 3 \\
\hline Pomiar 1 [mm] & 0,0152 & 0,0162 & 0,0115 \\
\hline Pomiar 2 [mm] & 0,0145 & 0,0149 & 0,0123 \\
\hline Pomiar 3 [mm] & 0,0149 & 0,0157 & 0,0121 \\
\hline Średnia & 0,0149 & 0,0156 & 0,0120 \\
\hline Średnia z 3 próbek & & $\mathbf{0 , 0 1 4 1}$ \\
\hline
\end{tabular}

\section{Podsumowanie}

Wytworzenie warstwy bazującej na związku typu Fe-Al, może w przyszłości znaleźć zastosowanie jako warstwa pośrednia do połączeń konstrukcji stalowych z elementami aluminiowymi. Obecnie jedynymi stosowanymi metodami do tego celu są: lutospawanie oraz metoda CMT (ang. Cold Metal Transfer) stosowana w urządzeniach Fronius.

W przemyśle nie stosuje się jeszcze metod z technologii spawania do wytwarzania połączeń stal-aluminium.

Stan naprężeń własnych w układzie warstwa-podłoże może odgrywać znaczącą rolę przy ocenie trwałości eksploatacyjnej omawianych warstw. Wyznaczone wartości naprężeń w warstwie Fe-Al osiągają maksymalną wartość 128 MPa przy granicy z podłożem stalowym. Zbudowany model numeryczny dla układu warstwa FeAl / podloże stalowe wykazał, że maksymalne ugięcie próbki na skutek przemieszczających się ściegów uległo przesunięciu w stosunku do pionowej osi symetrii próbki. Wartości wyznaczonego z modelu komputerowego ugięcia próbki w osi symetrii (środek szerokości próbki) mieściła się w zakresie błędu pomiaru tego ugięcia zmierzonego czujnikiem zegarowym w osi próbki. W złączu wystąpiła pewna relaksacja naprężeń spowodowana powstaniem odkształceń plastycznych w procesie oddziaływania spawalniczego źródła ciepła na materiał przetapiany.

Zastosowana metoda przetapiania mikroplazmowego daje możliwość wytwarzania in-situ warstw ochronnych bazujących na roztworze wtórnym Fe-Al. Budowa otrzymanych warstw oraz ich właściwości mechaniczne i użytkowe umożliwiają rozwój nowych kierunków ich zastosowań na elementy maszyn pracujące przy wysokich obciążeniach cieplnych i mechanicznym, w warunkach korozyjnych czy też w warunkach silnego zużycia ściernego.

\section{Literatura}

[1] Wiliama J.C.: Intermetallics for structural applications: potential, reality and roadahead, Structural Intermetallics, ed. M.V. Nathalat al., TMS 1997, pp. 3-8.

[2] Bystrzycki J., Varin R.A., Bojar Z.: Postępy w badaniach stopów na bazie uporządkowanych faz międzymetalicznych z udziałem aluminium, Inżynieria Materiałowa 1996, 5, s. 137-149.

[3] Gontarz G., Golański G., Chmielewski T.: Powłoki intermetaliczne z grupy Fe-Al wytwarzane metodami spawalniczymi, Mechanik Nr 08/09/2012 s. 769-771.

[4] Chmielewski T., Golański D.: The new method of in-situ fabrication of protective coatings based on FeAl intermetallic compounds. Journal of Engineering Manufacture Part B, April 2011, 225, pp. 611-616.

[5] Gontarz G., Chmielewski T., Golański D.: Modyfikacja natryskiwanych powłok aluminiowych na stali skoncentrowanym źródłem ciepła, Przegląd Spawalnictwa, 12/2011, s. 52-54.

[6] Chmielewski T., Golański D., Gontarz G.: Investigation of the residual stresses in composite Ti+Al2O3 coatings deposited by thermal spraying onto ceramic substrate, Composites Theory and Practice 12: 1(2012), pp. 26-32.
[7] Clyne T.W., Gill S.C.: Residual Stresses in Surface Coatings and Their Effects on Interfacial Debonding: A Review of Recent Work, J. Thermal Spray Technology, (1996), Vol. 5(4), pp. 401-418.

[8] Li. D, Lin. D., Liu Y.: Effect of temperature on tensile properties and dislocation structures of FeAl alloys, Material Science and Engineering, A249(1988), pp. 206-216.

[9] Reddy B.V., Deevi S.C.: Thermophysical properties of FeAl (Fe-40 at.\%Al), Intermetallics 8 (2000), pp. 1369-1376.

[10] Goldsmith A., Waterman T.E., Hirchorn H.J.: Handbook of thermophysical properties of solid materials, New York 1961.

[11] Chmielewski T., Golański D., Gontarz G.: Pomiar naprężeń własnych powłok metalicznych natryskiwanych termicznie. Przegląd Spawalnictwa 12/2011, s. 59-64. 